\title{
Retention Cyst
}

National Cancer Institute

\section{Source}

National Cancer Institute. Retention Cyst. NCI Thesaurus. Code C113736.

A cyst that is formed because of the blockage of the duct of a glandular organ. This results in the retention of the glandular secretions. 